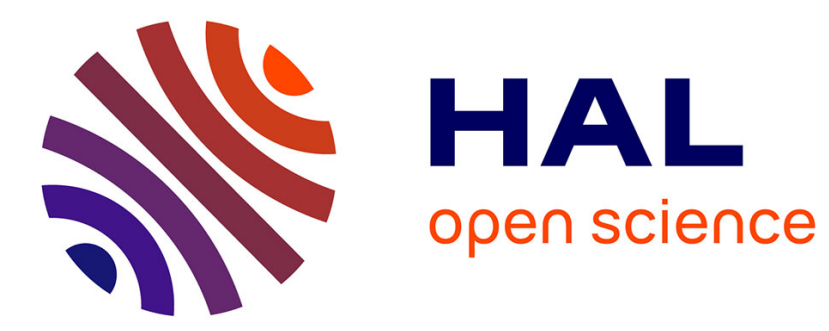

\title{
Toward a reverse hierarchy of halogen bonding between bromine and iodine
}

Emmanuel Aubert, Enrique Espinosa, Irène Nicolas, Olivier Jeannin, Marc

Fourmigué

\section{- To cite this version:}

Emmanuel Aubert, Enrique Espinosa, Irène Nicolas, Olivier Jeannin, Marc Fourmigué. Toward a reverse hierarchy of halogen bonding between bromine and iodine. Faraday Discussions, 2017, 203 (4), pp.389-406. 10.1039/C7FD00067G . hal-01619450

\section{HAL Id: hal-01619450 \\ https://hal-univ-rennes1.archives-ouvertes.fr/hal-01619450}

Submitted on 19 Oct 2017

HAL is a multi-disciplinary open access archive for the deposit and dissemination of scientific research documents, whether they are published or not. The documents may come from teaching and research institutions in France or abroad, or from public or private research centers.
L'archive ouverte pluridisciplinaire HAL, est destinée au dépôt et à la diffusion de documents scientifiques de niveau recherche, publiés ou non, émanant des établissements d'enseignement et de recherche français ou étrangers, des laboratoires publics ou privés. 


\section{Toward a reverse hierarchy of halogen bonding between bromine and iodine $\dagger$}

Emmanuel Aubert, ${ }^{a}$ Enrique Espinosa, ${ }^{* a}$ Irène Nicolas, ${ }^{b}$ Olivier Jeannin, ${ }^{b}$ and Marc Fourmigué $e^{* b}$

${ }^{a}$ Laboratoire CRM2, UMR CNRS 7036, Institut Jean Barriol, Université de Lorraine, BP 70239, 54506 Vandoeuvre-les-Nancy, France.E-mail: enrique.espinosa@univ-lorraine.fr

${ }^{b}$ Institut des Sciences Chimiques de Rennes (ISCR), UMR CNRS 6226, Université de Rennes

1, Campus de Beaulieu, 35042 Rennes, France.E-mail:marc.fourmigue@univ-rennes1.fr

$\dagger$ Electronic supplementary information (ESI) available: X-ray crystallographic data (in cif format), details of theoretical calculations with Table S1, Figures S1-S16. For ESI and crystallographic data in CIF or other electronic format see DOI: 10.1039/XXXX. 


\section{Abstract}

We compare here the halogen bond characteristics of bimolecular adducts involving either the $\mathrm{N}$-bromo- or the $\mathrm{N}$-iodosaccharin as strong halogen bond donors, with 4picoline as common XB acceptor. In the NBSac•Pic system, the bromine atom of NBSac is displaced toward the picoline, almost at median position between the two nitrogen atoms, $\mathrm{N}_{\text {sac }}$ and $\mathrm{N}^{\prime}$ Pic, with $\mathrm{N}_{\text {sac }}{ }^{\circ} \cdot \mathrm{Br}$ and $\mathrm{Br} \cdots \mathrm{N}^{\mathrm{N}}$ 'Pic distances at 2.073(6) and 2.098(6) ^ respectively. This extreme situation contrasts with the analogous iodine derivative, NISac•Pic, where the $\mathrm{NSac}-\mathrm{I}$ and $1.0 \cdot \mathrm{N}^{\prime}$ 'Pic distances amount to 2.223(4) and 2.301(4) A respectively. Periodic DFT calculations, and molecular calculations of adducts (PBEPBE-D2 aug-cc-pVTZ) either at the experimental frozen geometry or with optimization of the halogen position, indicate a more important degree of covalence (i.e. shared-shell character) in the adduct formed with the bromine atom. A stronger charge transfer to the picoline is also found for the bromine $(+0.27|e|)$ than for the iodine $(+0.18|e|)$ system. This inversion of halogen bond strength between $\mathrm{I}$ and $\mathrm{Br}$ finds its origin in the strong covalent character of the interaction in these adducts, in line with the strength of covalent $\mathrm{N}-\mathrm{Br}$ and $\mathrm{N}-\mathrm{I}$ bonds. Detailed characterization of the critical points (CPs) of the $L(\mathbf{r})=-\nabla^{2} \rho(\mathbf{r})$ function along bonding directions has permitted to distinguish that the adducts can be respectively described as "neutral" NISac/Pic and "intermediate" $\mathrm{NSac} / \mathrm{Br} / \mathrm{Pic}$, the latter with $\mathrm{Br}$ being close to formal equivalent

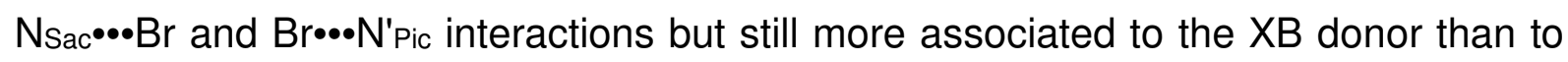
the picoline, as indicated by the topological and energetic properties of the $\rho(\mathbf{r})$ function at the bond critical points (BCPs). 


\section{Introduction}

In the recent years, halogen bonding $(\mathrm{XB})$ has been rediscovered as an efficient tool in solid state chemistry, to control and organize condensed phases into desired structures. ${ }^{1,2}$ The comparison and possible analogies with hydrogen bonding (HB) have revealed that halogen bonding can be as strong as and even more directional than $\mathrm{HB}$, as illustrated by the outcome of the competition between both interactions. ${ }^{3}$ These studies have provided a broad palette of 'tectons' or 'synthons', 4,5 allowing for remarkably effective supramolecular solid state synthetic strategies, very often based on the formation of cocrystals. ${ }^{6,7}$ In these systems, both theoretical calculations and experimental investigations have long established that stronger halogen bonds are recurrently observed with iodine rather than with bromine atoms as halogen bond donors, within a general sequence $\mathrm{I}>\mathrm{Br}>>\mathrm{Cl}>>\mathrm{F}^{8}$ It is for example well illustrated in the crystal structures of halocyanoacetylenes ${ }^{9}$ or 4 -halobenzonitriles, ${ }^{10}$ where notably shorter $\mathrm{X} \bullet \bullet \mathrm{N}$ distances are observed with $\mathrm{X}=\mathrm{I}$ than with $\mathrm{X}=\mathrm{Br}$ or $\mathrm{X}=\mathrm{Cl}$, despite opposite trend of their van der Waals radii. Nonetheless, if we turn our attention to the very strong halogen bonds found for example in halonium salts such as the archetypal halonium-pyridine $[\mathrm{Py}-\mathrm{X}-\mathrm{Py}]^{+}$ cations, ${ }^{11}$ we note that in these crystalline symmetrical systems, ${ }^{12,13}$ the reduction ratio for the $\mathrm{N} \bullet \bullet \mathrm{Br}$ bonds $(0.63)$ is actually smaller than for the $\mathrm{N} \bullet \bullet \mathrm{I}$ bonds (0.65). This intriguing observation prompted us to investigate this iodine/bromine evolution in similar systems where the halogen bond takes a partial covalent character.

We have indeed recently investigated non-symmetric structures where a very strong XB donor, namely $\mathrm{N}$-iodosaccharin (NISac) ${ }^{14}$ is faced with electron-rich pyridines such as 4picoline and 4-dimethylamino-pyridine (DMAP). We showed that NISac•DMAP could be actually better described under its ionic form, that is a saccharinate anion halogen bonded to the corresponding $\mathrm{N}$-iodopyridinium (Scheme 1), while the structural characteristics of the corresponding 4-picoline adduct, NISac•Pic, indicated a predominant neutral form. ${ }^{15}$ In order to evaluate the differences between iodine and bromine in such systems, we have investigated the nature of the N-bromosaccharin (NBSac) adducts with both 4-picoline and 4dimethylaminopyridine. The isolation of a crystalline adduct of NBSac with 4-picoline allows now for a very informative comparison of the relative role of the halogen atom in these neutral/ionic halogen-bonded systems, as detailed below. 


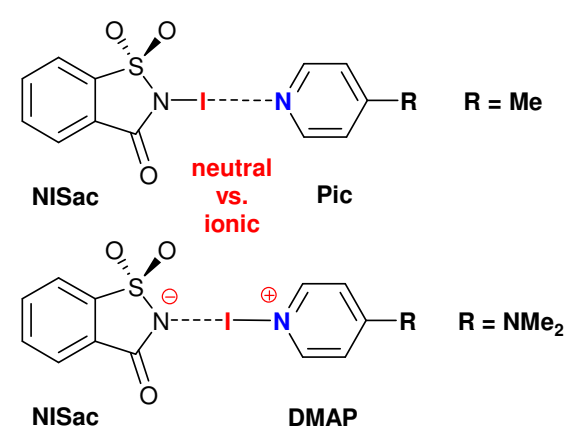

\section{Scheme 1}

\section{Results and Discussion}

\section{Syntheses}

The preparation of the NISac adducts has been described earlier. The NBSac adducts were obtained by vapour diffusion of hexane over a filtered solution of NBSac with two equivalents of either 4-dimethylaminopyridine (DMAP) or 4-picoline (Pic) dissolved in the appropriate solvent (Scheme 2). With the electron-rich DMAP, we were able to isolate only a few crystals of a transformed compound, where the pyridine is actually brominated in meta position. Single crystal X-ray structure determination showed that the isolated crystals, which are probably not representative of the whole batch, are actually the 3-bromo-4-dimethylaminopyridinium salt crystallizing with the saccharinate anion as counter ion. This result confirms that Nbromosaccharin is a stronger halogenating agent than the corresponding $\mathrm{N}$-iodo analog, since the corresponding adduct of DMAP with NISac has been readily isolated in the same conditions. ${ }^{15}$ This is in line with halogenation reactions of arenes or alkenes, which are successfully performed with NBSac, when NISac requires more activated, electron-rich, substrates. ${ }^{16}$ On the other hand, the reaction of NBSac with picoline afforded the expected 1:1 adduct, as confirmed by NMR and single crystal X-ray structure determination, as detailed below. 


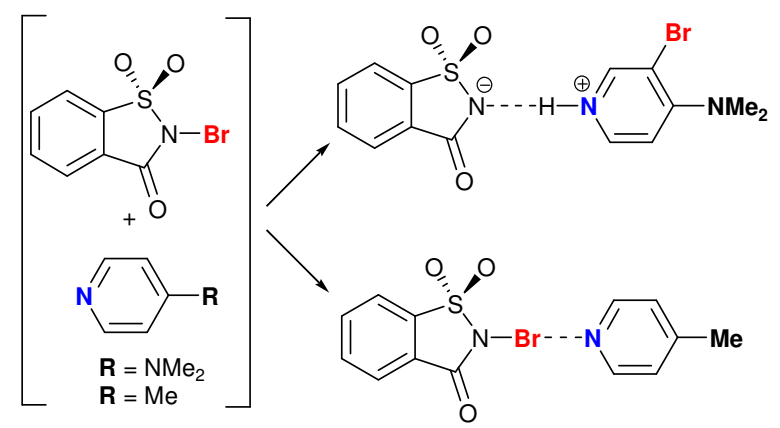

Scheme 2.

\section{Solid state structures}

The solid state organization of the 3-bromo-4-dimethylaminopyridinium salt (Figure 1) is characterized by a chain motif built out of both strong hydrogen and strong halogen bonding interactions, with the carbonyl group of the saccharinate anion acting simultaneously as hydrogen bond and halogen bond acceptor. It provides an example where a nucleophilic moiety (here the carbonyl group) is simultaneously involved in both $\mathrm{HB}$ and $\mathrm{XB},{ }^{17,18}$ an important point in biological systems. ${ }^{19}$ Bond distances and angles indicate strong intermolecular interactions, based on the short interatomic distances $v s$. the sum of van der Waals radii, and on their directionality.

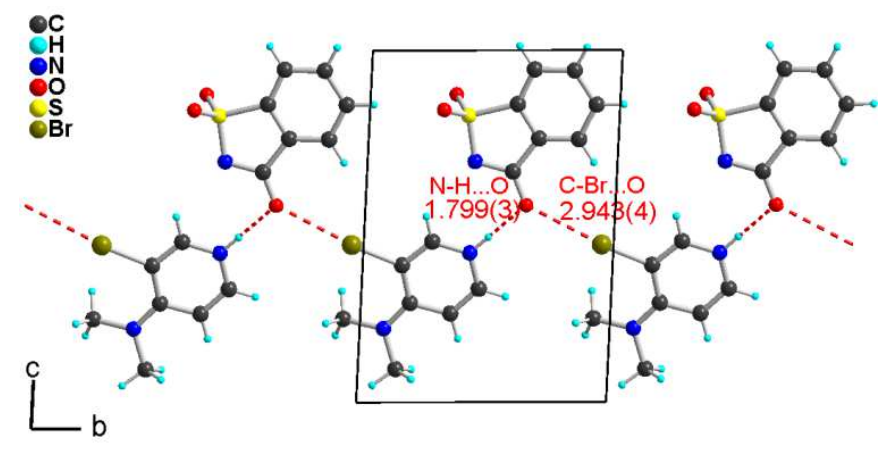

Fig. 1 Projection view along the a axis of a detail of the unit cell of the saccharinate salt of 3bromo-4-dimethylaminopyridinium. Pertinent intermolecular bond distances and angles for hydrogen bonding $\left(\mathrm{H} \cdots \cdot \mathrm{O}: 1.799 \AA, \mathrm{N}-\mathrm{H} \cdots \cdot \mathrm{O}: 177.0^{\circ}\right)$ and halogen bonding interactions

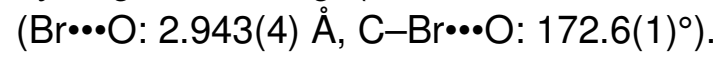

The 1:1 adduct NBSac•Pic crystallizes in the triclinic system, space group $P \overline{1}$, with one adduct in general position, characterized by a very short and directional Br $\bullet \bullet \mathrm{N}_{\text {Pic }}$ halogen bond and a dipole moment of 8.77 Debye (Figure 2a). The relevant structural features are collected in Table 1, together with those of the NISac adduct (Figure $2 b$ ) for comparison. The orientation of the dipolar moment with respect to the $\mathrm{N}_{\mathrm{Sac}} \bullet \bullet \mathrm{X} \bullet \bullet \mathrm{N}_{\text {Pic }}^{\prime}$ axis $(\mathrm{X}=\mathrm{Br}, \mathrm{I})$, with an angle of $\approx$ 
$15^{\circ}$, illustrates the stronger electron-withdrawing effect of the $\mathrm{SO}_{2}$ group relative to the $\mathrm{C}=\mathrm{O}$ one.
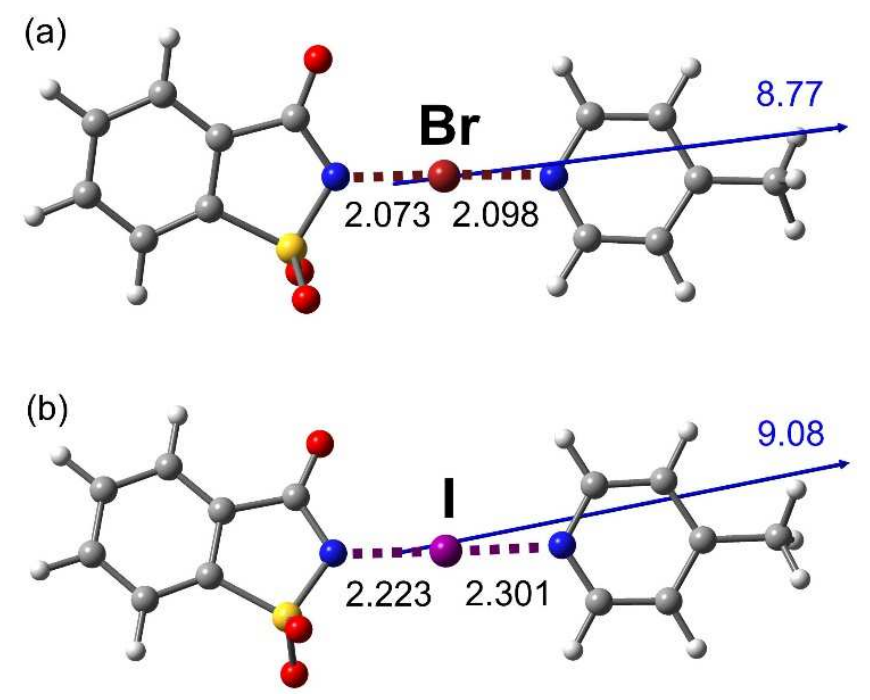

Fig. 2 Halogen bonding interactions in (a) NBSac.Pic and (b) NISac.Pic. Distances are given in $\AA$. Arrows and values correspond to the orientation and the magnitude (in Debye) of the dipolar moments of the adducts calculated at frozen experimental geometries.

Table 1 Relevant distances and angles of the $\mathrm{N}_{\mathrm{Sac}}-\mathrm{X} \cdot \cdots \mathrm{N}_{\mathrm{Pic}}$ halogen bond in the co-crystals with NBSac and NISac for X-ray data collected at $150 \mathrm{~K} . d_{1}=\mathrm{N}_{\mathrm{Sac}}-\mathrm{X}$ distance, $d_{2}=\mathrm{X} \cdot \cdots \mathrm{N}_{\mathrm{Pic}}$ distance, $d_{1}+d_{2}=\mathrm{N}_{\mathrm{Sac}} \cdot \cdots \cdot \mathrm{N}_{\text {Pic }}$ distance (the interaction is very close to linear). The dihedral angle is calculated between the five-membered ring of the saccharin and the pyridine ring.

\begin{tabular}{cccccccc}
\hline & $\begin{array}{c}d_{1} \\
\left(\mathrm{~N}_{\mathrm{Sac}}-\right. \\
\mathrm{X}) \\
(\AA)\end{array}$ & $\begin{array}{c}d_{2} \\
\left(\mathrm{X} \bullet \bullet \mathrm{N}_{\mathrm{Pic}}\right) \\
(\AA)\end{array}$ & $d_{1}-d_{2}$ & $\mathrm{~N}_{\mathrm{Sac}}-\mathrm{X} \bullet \bullet \mathrm{N}_{\mathrm{Pic}}$ & $\begin{array}{c}d_{1}+d_{2} \\
\left(\mathrm{~N}_{\mathrm{Sac}} \cdots \bullet \mathrm{N}_{\text {Pic }}\right)\end{array}$ & $\begin{array}{c}\text { Dihedral } \\
\text { angle } \\
\left({ }^{\circ}\right)\end{array}$ & Ref. \\
\hline $\mathrm{X}=\mathrm{Br}$ & $2.073(6)$ & $2.098(6)$ & -0.025 & $178.74(8)$ & $4.171(12)$ & $14.56(7)$ & $\begin{array}{c}\text { this } \\
\text { work }\end{array}$ \\
$\mathrm{X}=\mathrm{I}$ & $2.223(4)$ & $2.301(4)$ & -0.078 & $178.1(1)$ & $4.523(7)$ & $18.8(1)$ & 15 \\
\hline
\end{tabular}

Note that NBSac $\bullet$ Pic is not isostructural with the analogous NISac $\bullet$ Pic adduct, a possible consequence of (i) an overall slightly shorter molecule (by $0.35 \AA$ ), (ii) a decreased dihedral angle between the two planar saccharinate and picoline moieties and (iii) a different organization of the dipoles in the crystal structures of the adducts. The latter associate in both compounds into head-to-tail dimers, driven by dipole-dipole interactions and most probably through favoured $\pi-\pi$ picoline-saccharin interactions (Figures $3 \mathrm{a}$ and $3 \mathrm{~b}$ ). Supramolecular organization of the head-to-tail dimers differs in both cases. While in NBSac•Pic, the head-totail chains of dipoles further interact with closer chains of opposite oriented dipoles (Figure 3c) 
through picoline-picoline or saccharin-saccharin $\pi-\pi$ interactions forming layers parallel to (111) planes (Figure 3a), a different organization is observed in NISac•Pic, where picolinesaccharin $\pi-\pi$ interactions develop between head-to-tail dimers along the stacking $a$-axis. The latter interact with neighbouring chains of stacked dimers (situated in front of and behind the chains represented in Figure 3d) by means of lateral favourable dipole-dipole interactions, thanks to a gliding disposition of similarly oriented dipoles which approach lateral head-to-tail interactions. Head-to-head and tail-to-tail dipoles observed in Figure 3d are connected through these lateral interactions with neighbouring chains. The analysis of the charge distribution of both systems (see below) might help us to rationalize these differences.

(a)

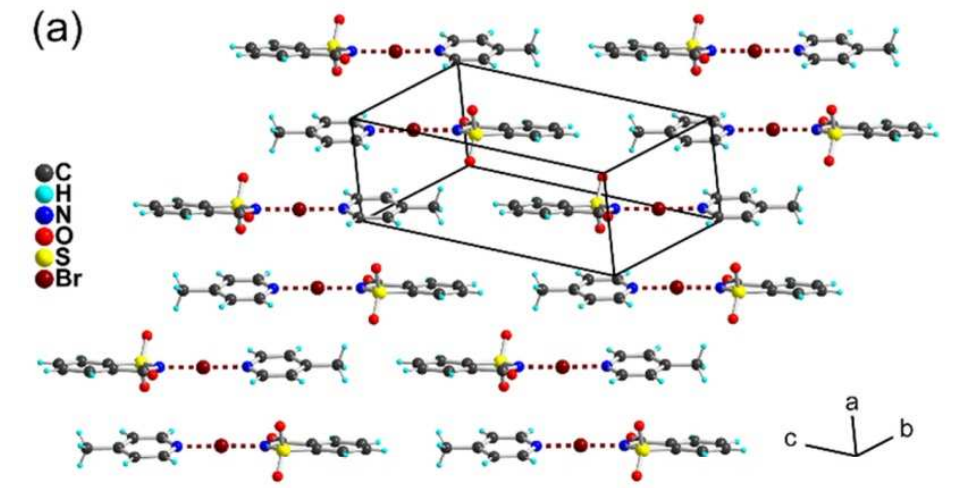

(b)

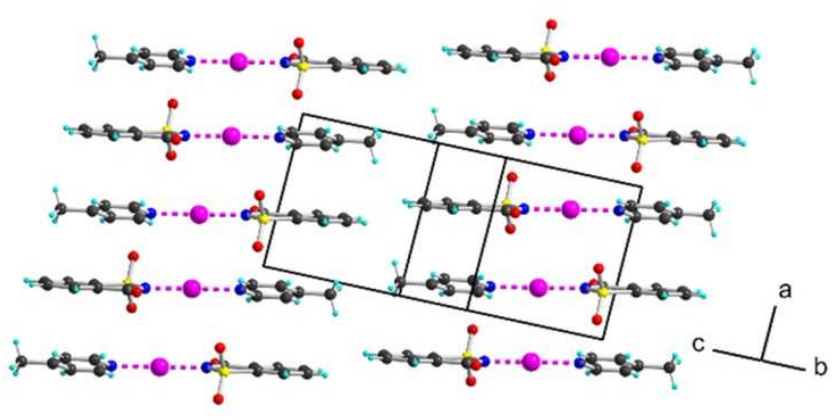

(c)

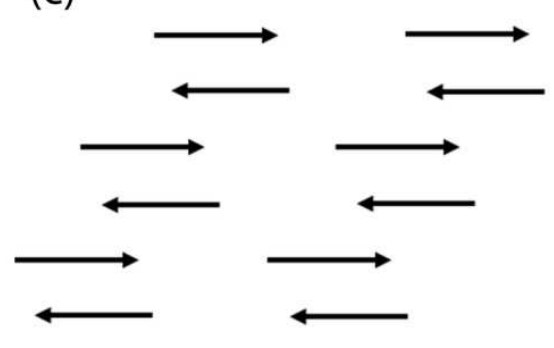

(d)

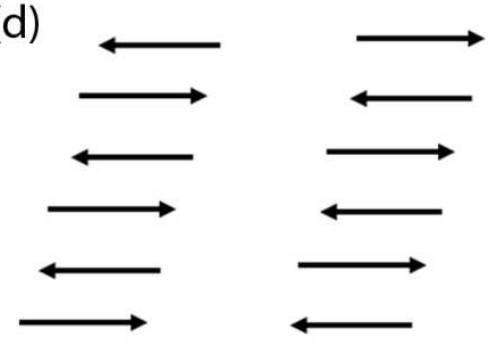

Fig. 3 Detail of the solid state organization of (a) NBSac·Pic and (b) NISac·Pic. Arrows in (c) and (d) indicate the organization of the dipolar moments in the crystal structures of (a) and (b), respectively.

We note that the halogen bond interaction is in every case highly linear and short, with $\mathrm{X} \bullet \bullet \mathrm{N}_{\text {Pic }}$ distances much shorter than the sum of the van der Waals radii. Compared indeed to the sum of the van der Waals radii $(\mathrm{Br}+\mathrm{N}=1.85+1.55=3.40 \AA ; \mathrm{I}+\mathrm{N}=1.98+1.55=3.53$ $\AA$ ), the reduction ratio for the $\mathrm{X} \bullet \bullet \mathrm{N}_{\text {Pic }}$ distance amounts to 0.652 with NISac and to an even smaller value of 0.617 with NBSac. Also, with NBSac, the two $\mathrm{N}_{\mathrm{Sac}}-\mathrm{Br}$ and Br॰••N $\mathrm{N}_{\text {Pic }}$ distances are almost equal, respectively 2.073(6) and 2.098(6) $\AA$. This indicates that the bimolecular 
NBSac $\bullet$ Pic adduct is most probably very close to an ionic description of a N-bromo-4picolinium salt, halogen bonded to a saccharinate anion, a situation encountered only up to now in the reported association of $\mathrm{N}$-iodosaccharin with the notably more electron-rich 4dimethylaminopyridine (Scheme 1). This highly symmetric bromine position contrasts with that of the NISac $\bullet P i c$ adduct, where the $\mathrm{N}_{\mathrm{Sac}}-\mathrm{I}$ and I $\bullet \bullet \mathrm{N}_{\text {Pic }}$ distances amount respectively to 2.223(4) and 2.301(4) $\AA$ at the same temperature (150 K). This tends to indicate that with the very same chemical environment (saccharinate and 4-picoline), the replacement of iodine by bromine favours the displacement of the halogen atom toward the picoline to give a more ionic structure, or in other words that in these "halonium" systems, the halogen bonding interactions would be stronger with bromine than with iodine.

\section{Theoretical investigations}

In order to rationalize the above observations and to compare the role of the halogen atom ( $\mathrm{Br} v s . \mathrm{I})$ in these systems, periodic DFT calculations (CASTEP 8.0), ${ }^{20}$ and molecular calculations of adducts (PBEPBE-D2 aug-cc-pVTZ) either at the experimental frozen geometry or with optimization of the halogen position, were conducted. Such DFT theoretical calculations have been already successfully used to investigate environment effects on the I-adducts. ${ }^{15,21}$ In addition, similar calculations have also shown to provide charge density distributions very comparable with those experimentally determined from high-resolution low-temperature single-crystal X-ray diffraction data. ${ }^{22}$

The $\mathrm{N}_{\text {Sac }}-\mathrm{X}$ and $\mathrm{X} \bullet \bullet \mathrm{N}^{\prime}$ Pic distances obtained with periodic DFT calculations carried out by optimizing all the atomic positions while keeping frozen the experimental unit-cell parameters are given as d(periodic) in Table 2. For both NBSac and NISac adducts, theoretical and experimental $\mathrm{N}_{\mathrm{Sac}}-\mathrm{X}$ and $\mathrm{X} \bullet \bullet \mathrm{N}^{\prime}$ ic distances are comparable, with theoretical values very close to and systematically slightly larger than the experimental ones (differences for $\mathrm{N}_{\mathrm{Sac}}-\mathrm{X}$ and $\mathrm{X} \bullet \bullet \mathrm{N}^{\prime}$ Pic are $0.03-0.04 \AA$ and $0.01 \AA$, respectively). As already noted earlier, ${ }^{15}$ these periodic calculations reproduce well the experimental halogen position between the two nitrogen atoms.

Besides, molecular calculations (PBEPBE-D2 aug-cc-pVTZ) of adducts at the experimental frozen geometry have been used to evaluate the topological properties of the electron density distribution $\rho(\mathbf{r})$ at $\mathrm{N}_{\mathrm{Sac}}-\mathrm{X}$ and $\mathrm{X} \bullet \bullet \mathrm{N}^{\prime}$ Pic bond critical points (BCPs) by using the Quantum Theory of Atoms in Molecules (QTAIM) methodology. ${ }^{23}$ Table 2 gathers the pertinent calculated parameters for the two adducts. Afterwards, the halogen atom position was optimized, keeping frozen the rest of the atoms. The theoretically calculated distances $\mathrm{N}_{\mathrm{Sac}}-\mathrm{X}$ 
and $\mathrm{X} \bullet \bullet \mathrm{N}_{\text {Pic }}^{\prime}$ thus obtained $[\mathrm{d}($ opt. X)] (Table 2) locate the halogen atom much closer to the saccharin than in the experimental geometry, indicating the important role of the crystal surroundings to the final adduct geometry. Then, upon the action of a homogenous electric field (E) that was applied along the linear $\mathrm{N}_{\mathrm{Sac}} \bullet \bullet \mathrm{X} \bullet \bullet \mathrm{N}^{\prime}$ Pic direction, the $\mathrm{X}$-position between $\mathrm{N}_{\mathrm{Sac}}$ and $\mathrm{N}^{\prime}$ Pic has been progressively shifted as a function of the $\mathcal{\varepsilon}$-magnitude. The electric field able to recover the experimental $\mathrm{N}_{\mathrm{Sac}}-\mathrm{X}$ and $\mathrm{X} \cdot \bullet \mathrm{N}^{\prime}$ Pic distances observed in the crystalline phase of the adduct, along with the corresponding integrated QTAIM net charges (Q) calculated for X and for the donor/acceptor fragments with $\mathrm{X}$ belonging to one or another, are also given in Table 2.

The geometrical distances of $\mathrm{X}$ to $\mathrm{N}_{\mathrm{Sac}}$ and $\mathrm{N}$ 'Pic are longer to those found in the isolated monomers NXSac and XPic $(\mathrm{X}=\mathrm{Br}, \mathrm{I})$. Indeed, the differences $\Delta$ between the crystal and gas phases for $\mathrm{N}_{\mathrm{Sac}}-\mathrm{X}$ are $\Delta(\mathrm{NSac}-\mathrm{Br})=2.073-1.848=+0.225 \AA$ and $\Delta(\mathrm{NSac}-\mathrm{I})=2.223-2.046$ $=+0.177 \AA$, while the corresponding values for $\mathrm{X}^{-N^{\prime}}{ }^{\prime}$ Pic are $\Delta\left(\mathrm{Br}-\mathrm{N}^{\prime}{ }_{\text {Pic }}\right)=2.098-1.880=$ $+0.218 \AA$ and $\Delta\left(\mathrm{I}_{-} \mathrm{N}^{\prime}{ }^{\prime}\right.$ Pic $)=2.301-2.091=+0.210 \AA$ (see Table $\mathrm{S} 1$ in ESI and reference 15$)$. Since the experimental distances show $\mathrm{N}_{\mathrm{Sac}}-\mathrm{X}<\mathrm{X} \bullet \bullet \mathrm{N}^{\prime}$ Pic $(\mathrm{X}=\mathrm{Br}, \mathrm{I})$, the $\mathrm{X}$ transfer between donor and acceptor moieties seems not still occurred from a geometrical point of view in any of the adducts, in spite the $\mathrm{N}_{\mathrm{Sac}}-\mathrm{X}$ bond has been significantly weakened.

Table 2 Internuclear $\mathrm{N}_{\mathrm{SAc}}-\mathrm{X}$ and $\mathrm{X} \cdots \mathrm{N}^{\prime}$ 'pic distances: Experimentally determined (italic) and theoretical calculated ( $d$ (periodic) and $d(o p t . X)$, see text). At frozen experimental geometries (including $X$ ), the gathered theoretical QTAIM topological properties of the electron density $\rho(\mathbf{r})$ at BCPs are: the electron density ( $\left.\rho_{\mathrm{BCP}}\right)$, its Laplacian $\left(\nabla^{2} \rho_{\mathrm{BCP}}\right)$, the total electron energy density $\left(H_{\mathrm{BCP}}=V_{\mathrm{BCP}}+G_{\mathrm{BCP}}\right)$ and the ratio between the electron potential $\left(V_{\mathrm{BCP}}\right)$ and kinetic $\left(G_{\mathrm{BCP}}\right)$ energy densities $\left(\left|V_{\mathrm{BCP}}\right| / G_{\mathrm{BCP}}\right)$, as well as their values normalized by $\rho_{\mathrm{BCP}}$. After optimization of the halogen atom position, while keeping frozen the rest of the atoms in the adduct, $\varepsilon(\mathrm{GV} / \mathrm{m})$ and $Q(|e|)$ represent the magnitude of the electric field able to recover the experimental $\mathrm{N}_{\mathrm{SAc}^{-}}$ $X$ and $X \cdots N^{\prime}$ Pic distances observed in the crystalline phase of the adduct and the integrated QTAIM net charges calculated for donor/acceptor fragments, with $X$ belonging to donor or acceptor.

\begin{tabular}{|c|c|c|}
\hline Distances $(\AA)$ & NBSac•Pic & NISac•Pic ${ }^{a}$ \\
\hline Exp. $d\left(N_{S a c}-X\right)$ & 2.073 & 2.223 \\
\hline Calc d(periodic) & 2.114 & 2.264 \\
\hline Calc d(opt. X) & 1.962 & 2.154 \\
\hline $\operatorname{Exp} . d\left(X \bullet \bullet N^{\prime} P i c\right)$ & 2.098 & 2.300 \\
\hline Calc d(periodic) & 2.110 & 2.307 \\
\hline Calc d(opt. X) & 2.209 & 2.369 \\
\hline
\end{tabular}




\begin{tabular}{|c|c|c|}
\hline $\begin{array}{l}\text { Topological properties } \\
\text { at experimental geometry }\end{array}$ & & \\
\hline$\rho_{\text {BCP }} N_{S a c}-X\left(e . \AA^{-3}\right)$ & 0.715 & 0.603 \\
\hline$\rho_{\text {ВСР }} X \bullet \bullet N^{\prime}$ Pic $\left(e . \AA^{-3}\right)$ & 0.676 & 0.518 \\
\hline$\nabla^{2} \rho_{\mathrm{BCP}} \mathrm{N}_{\mathrm{Sac}}-\mathrm{X}\left(\mathrm{e} . \AA^{-5}\right)$ & 1.91 & 2.45 \\
\hline$\nabla^{2} \rho_{\text {BCP }} X \bullet \bullet N^{\prime}$ Pic $\left(\right.$ e. $\left.\AA^{-5}\right)$ & 2.69 & 2.81 \\
\hline$\left(\nabla^{2} \rho / \rho\right)_{\mathrm{BCP}} \mathrm{N}_{\mathrm{Sac}}-\mathrm{X}\left(\AA^{-2}\right)$ & 2.67 & 4.06 \\
\hline$\left(\nabla^{2} \rho / \rho\right)_{\text {BCP }} X \bullet \bullet N^{\prime}{ }_{\text {Pic }}\left(\AA^{-2}\right)$ & 3.98 & 5.42 \\
\hline$H_{\mathrm{BCP}} \mathrm{N}_{\mathrm{Sac}}-\mathrm{X}$ (a.u.) & -0.0432 & -0.0352 \\
\hline$H_{\mathrm{BCP}} \mathrm{X} \bullet \bullet \mathrm{N}^{\prime}$ Pic (a.u.) & -0.0387 & -0.0254 \\
\hline$(H / \rho)_{\text {BCP }} N_{S a c}-X$ (a.u.) & -0.4077 & -0.1103 \\
\hline$(H / \rho)_{\text {ВСР }} X \bullet N^{\prime}$ Pic $($ a.u. $)$ & -0.1082 & -0.0927 \\
\hline$|V| / \mathrm{G} \mathrm{N}_{\mathrm{Sac}}-\mathrm{X}$ & 1.686 & 1.581 \\
\hline$|V| / G X \bullet \bullet N^{\prime}$ Pic & 1.581 & 1.466 \\
\hline \multicolumn{3}{|l|}{$\begin{array}{l}\text { Adduct in gas-phase } \\
\text { at exp. geometry } \\
\text { with } X \text { optimization upon } \varepsilon\end{array}$} \\
\hline$\varepsilon(\mathrm{GV} / \mathrm{m})$ & 2.96 & 2.35 \\
\hline$Q(\mathrm{X})(|e|)$ & +0.29 & +0.45 \\
\hline$Q(\mathrm{NXSac} / \mathrm{Pic})(|e|)$ & \pm 0.27 & \pm 0.18 \\
\hline$Q(\mathrm{NSac} / \mathrm{X}-\mathrm{Pic})(|e|)$ & \pm 0.56 & \pm 0.64 \\
\hline
\end{tabular}

a See ref. 15

For both adducts, the topological properties at BCPs confirm that $\mathrm{X}(\mathrm{X}=\mathrm{I}, \mathrm{Br})$ is still remaining at the saccharin side, showing a greater quantity of electron density in the bonding regions of $\mathrm{N}_{\mathrm{Sac}}-\mathrm{X}\left[\rho_{\mathrm{BCP}}\left(\mathrm{N}_{\mathrm{Sac}}-\mathrm{X}\right)>\rho_{\mathrm{BCP}}\left(\mathrm{X} \bullet \bullet \mathrm{N}_{\mathrm{Pic}}^{\prime}\right)\right]$ and with less depleted character $\left[\nabla^{2} \rho_{\mathrm{BCP}}\left(\mathrm{N}_{\mathrm{Sac}}-\mathrm{X}\right)<\nabla^{2} \rho_{\mathrm{BCP}}\left(\mathrm{X} \cdot \bullet^{-} \mathrm{N}_{\mathrm{Pic}}^{\prime}\right)\right.$, with $\nabla^{2} \rho_{\mathrm{BCP}}>0$ in both cases]. The same conclusion can be drawn from the negative values of the total electron energy density $\left[H_{\mathrm{BCP}}\left(\mathrm{N}_{\mathrm{Sac}}-\mathrm{X}\right)<\right.$ $H_{\mathrm{BCP}}\left(\mathrm{X} \bullet \bullet \mathrm{N}^{\prime}\right.$ Pic $\left.)\right]$, or equivalently from the ratio between the electron potential $V$ and kinetic $G$ energy densities $\left[\left|V_{\mathrm{BCP}} / G_{\mathrm{BCP}}\left(\mathrm{N}_{\mathrm{Sac}}-\mathrm{X}\right)>\right| V_{\mathrm{BCP}} \mid / G_{\mathrm{BCP}}\left(\mathrm{X} \bullet \bullet \mathrm{N}^{\prime}{ }_{\mathrm{Pic}}\right)\right]$, both measuring the balance between $V$ and $G\left(H_{\mathrm{BCP}}=V_{\mathrm{BCP}}+G_{\mathrm{BCP}}\right)$ and indicating a stronger bonding interaction at the 
saccharin side. Indeed, as an energy density is dimensionally equivalent to a force per unit area (i.e. a pressure), $\mathrm{V}_{\mathrm{BCP}}$ can be interpreted as the pressure exerted by the system to concentrate electrons in the bonding region, strengthening the interaction. On the other side, balancing the concentration of electrons induced by $V_{\mathrm{BCP}}, G_{\mathrm{BCP}}$ is the pressure exerted by these electrons against the atomic basins in the interaction, depleting de charge and therefore weakening the interaction. $V_{\mathrm{BCP}}$ and $G_{\mathrm{BCP}}$ are connected to each other, and any increase of $V_{\mathrm{BCP}}$ is concomitantly followed by the corresponding increase of $G_{\mathrm{BCP}}$ as a reaction, because a larger concentration of electrons leads to a more important electron-electron repulsion and therefore to a larger electron mobility (to deplete the charge), increasing $G_{\mathrm{BCP}} \cdot{ }^{24} \mathrm{Hence}$, in the balance between these two energetic properties, the greater is the excess of $V_{\mathrm{BCP}}$ with respect to $G_{\mathrm{BCP}}$, the greater is the strengthening of the interaction they characterize.

The reported topological and energetic properties at BCP point that $\mathrm{N}_{S a c}-\mathrm{X}$ and $\mathrm{X} \cdot \bullet \mathrm{N}^{\prime} \mathrm{Pic}$ interactions exhibit an intermediate character between pure closed-shell $\left(\nabla^{2} \rho_{\mathrm{BCP}}>0, H_{\mathrm{BCP}}<0\right.$, $\left.\left|V_{\mathrm{BCP}}\right| / G_{\mathrm{BCP}}<1\right)$ and pure shared-shell interactions $\left(\nabla^{2} \rho_{\mathrm{BCP}}<0, H_{\mathrm{BCP}}<0,\left|V_{\mathrm{BCP}}\right| / G_{\mathrm{BCP}}>2\right)$, thus belonging to the region $\left(\nabla^{2} \rho_{\mathrm{BCP}}>0, H_{\mathrm{BCP}}<0,1<\left|V_{\mathrm{BCP}}\right| / G_{\mathrm{BCP}}<2\right)$ where the electron density redistributes either to break or to form a chemical bond. ${ }^{25}$ In addition, comparing with the corresponding properties of the NBSac and NISac monomers in gas-phase (see Table S1 in ESI), the $\mathrm{N}_{\mathrm{Sac}}-\mathrm{X}$ bond has been significantly weakened in the adduct, which decreases the value of the electron density in the bonding region and leaves the region of pure shared-shell interactions as denoted by the topological and energetic properties at BCP (experimental/relaxed geometry for $\mathrm{N}_{\mathrm{Sac}}-\mathrm{Br}$ and $\mathrm{N}_{\mathrm{Sac}}-\mathrm{I}$ : $\rho_{\mathrm{BCP}}\left(\mathrm{e} . \AA^{-3}\right)=0.715 / 1.138$ and $0.603 / 0.856, \nabla^{2} \rho_{\mathrm{BCP}}\left(\mathrm{e} . \AA^{-5}\right)=1.91 /-0.85$ and $2.45 / 2.72, H_{\mathrm{BCP}}($ a.u. $)=-0.043 /-0.110$ and $0.035 /-0.067,\left|V_{\mathrm{BCP}}\right| / G_{\mathrm{BCP}}=1.686 / 2.087$ and $\left.1.581 / 1.703\right)$. It should be noted that the $\mathrm{N}_{\mathrm{Sac}}-\mathrm{I}$ bond in the monomer exhibits $\nabla^{2} \rho_{\mathrm{BCP}}>0$ (and therefore $\left|V_{\mathrm{BCP}}\right| / G_{\mathrm{BCP}}<2$ from the local form of the virial theorem) as a consequence of the highly depleted valence electrons of iodine, a result already observed in the I-I bonds of $\mathrm{I}_{2}$ and $\mathrm{I}_{3}{ }^{-}$molecules. ${ }^{26}$ As in the latter, the shared-shell character of the $\mathrm{N}_{\mathrm{Sac}}-\mathrm{I}$ bond exhibits from the appearance of the topological $(3,-3) \mathrm{CP}$ of the $L$ $=-\nabla^{2} \rho$ function in the bonding region (see Figures S1-S10 in ESI).

On the other hand, the difference between the structural distances $\Delta=\mathrm{d}\left(\mathrm{X} \bullet \bullet \mathrm{N}_{\text {Pic }}^{\prime}\right)-$ $\mathrm{d}\left(\mathrm{N}_{\mathrm{Sac}}-\mathrm{X}\right)$ observed for bromo and iodo adducts $(\Delta=0.025$ and $0.077 \AA$, respectively), seems to indicate that the transfer is closer to occur with $\mathrm{Br}$, as pointed out above. In order to assess this hypothesis, we compare hereafter the electron properties at the BCPs of the Br- and Iadducts normalized to charge density unit. Indeed, this normalization is needed to compare the 
adducts, as they involve $\mathrm{X}$-atoms with different number of electrons and electron shells. ${ }^{27}$ The comparison of the $\nabla^{2} \rho_{\mathrm{BCP}} / \rho_{\mathrm{BCP}}$ values at the donor and at the acceptor sides of $\mathrm{X}$ in the adducts (Table 2), shows that the electron distribution is less depleted for $\mathrm{Br}$ than for $\mathrm{I}$ $\left[\nabla^{2} \rho_{\mathrm{BCP}} / \rho_{\mathrm{BCP}}\left(\mathrm{N}_{\mathrm{Sac}}-\mathrm{Br}\right)<\nabla^{2} \rho_{\mathrm{BCP}} / \rho_{\mathrm{BCP}}\left(\mathrm{N}_{\mathrm{Sac}}-\mathrm{I}\right]\right.$ and $\nabla^{2} \rho_{\mathrm{BCP}} / \rho_{\mathrm{BCP}}\left(\mathrm{Br} \bullet \bullet N^{\prime}{ }_{\mathrm{Pic}}\right)<$ $\nabla^{2} \rho_{\mathrm{BCP}} / \rho_{\mathrm{BCP}}\left(\left[\bullet \bullet N^{\prime}\right.\right.$ Pic $)$ ), indicating a more important degree of covalence (i.e. shared-shell character) in the adduct formed with the bromine atom. An equivalent conclusion can be also drawn from the energetic properties, showing more negative $H_{\mathrm{BCP}} / \rho_{\mathrm{BCP}}$ and larger $\left|V_{\mathrm{BCP}}\right| / G_{\mathrm{BCP}}$ values at both sides of the halogen atom in the Br-adduct (Table 2) (the latter descriptor is already normalized, as it is strictly equal to $\left.\left(\mid V_{\mathrm{BCP}} / \rho_{\mathrm{BCP}}\right) /\left(G_{\mathrm{BCP}} / \rho_{\mathrm{BCP}}\right)\right)$. Hence, with $\mathrm{Br}$, the more important shared-shell character at the acceptor side is balanced with a stronger interaction at the donor side, pointing the significant tightening in the Br-adduct at the origin of the $\mathrm{Br}$ position closer than I to the acceptor. Such a strengthening of the halogen bond interaction with bromine does not match with the usually recognized trend that halogen bonds are stronger with iodine than with bromine atoms in comparable systems. It has been only rarely observed, in symmetric bis(pyridine)halonium systems ${ }^{12,13}$ and, more recently, in pyridine adducts with other strong halogen bond donors, namely between dibromo- and diiodo-hydantoins. ${ }^{28}$ It finds its origin in the strong covalent character of the interaction in these adducts, in line with the bond strength of diatomic N-Br $\left(67 \mathrm{kcal} \mathrm{mol}^{-1}\right)$ and $\mathrm{N}-\mathrm{I}\left(38 \mathrm{kcal} \mathrm{mol}^{-1}\right)$ molecules. ${ }^{29,30}$ The observed trend in the comparison of Br- and I-adducts is even more striking when looking at the maximum electrostatic potential values (ESP) retrieved in the sigma-hole regions of NISac and NBsac monomers (see Figures S11-S12 in ESI), which indicates more important electrostatic interactions for NISac than for NBsac (maximum ESP on the 0.002 a.u. isodensity surface of NISac and NBsac is 0.0853 a.u. and 0.0674 a.u., respectively).

The degree of ionicity of both adducts can be also evaluated by the applied electric field which is needed to retrieve the experimental position of $\mathrm{X}$ within the dimer. This field is miming the effect of the crystalline electric field and, therefore, reflects the overall separation of charges within the crystal (the greater the field, the greater separation of donor and acceptor net charges, and therefore the greater is the crystalline ionicity). Formally, the distribution of charges within the adducts can be performed by considering either $\mathrm{N}_{\mathrm{Sac}}-\mathrm{X} / \mathrm{Pic}, \mathrm{N}_{\mathrm{Sac}} / \mathrm{X}-\mathrm{Pic}$ or $\mathrm{N}_{\mathrm{Sac}} / \mathrm{X} / \mathrm{Pic}$ moieties. Accordingly, the calculated net charges correspond to $-0.27 /+0.27,-0.56 /+0.56$ or $-0.56 /+0.29 /+0.27$ for the Br-adduct, and $-0.18 /+0.18,-0.64 /+0.64$ or $-0.64 /+0.45 /+0.18$ for the I-adduct (Table 2). If $\mathrm{X}$ is not still transferred, as previously concluded, only the first case should be considered. Accordingly, the crystalline ionicity determined by the final separation 
of charges between donor and acceptor molecules in NXSac/Pic is more important for the $\mathrm{Br}$ than for the I-adduct ( \pm 0.27 vs. $\pm 0.18 e$ ), which corresponds indeed to a larger electric field for the former (2.96 vs. $2.35 \mathrm{GV} / \mathrm{m}$, Table 3).

The dipole moments of the $\mathrm{Br}$ - and I-adducts $(\mu=8.77$ and $9.08 \mathrm{D}$, respectively, see also Figure 2) indicate that, in spite of a more important charge separation in the former $( \pm 0.27 v s$. $\pm 0.18 \mathrm{e}$ ), the total dipole moment is slightly larger in the latter. As a consequence of the dipole moment definition $(\mu=q \cdot d)$, this trend is the consequence of a larger distance $d$ between the centres of positive and negative charges $( \pm q)$ in the I-adduct, which is $0.35 \AA$ longer, overcoming a smaller quantity of charge separation in the donor-acceptor complex. Interestingly, the net charges of $\mathrm{Br}$ and I atoms in the adducts remain almost constant with respect to those observed in the NBSac and NISac monomers, $(\mathrm{Br}=+0.29 /+0.29|e|$ and $\mathrm{I}=$ $+0.45 /+0.43|e|$ for adduct/monomer systems, see Table S1 in ESI). This result indicates that neither the formation of the adduct, nor the effect of the crystalline environment are able to induce further charge transfer from $X$ during the weakening of the $N_{S a c}-X$ bond in the early stages of the X-transfer. Moreover, the net charge of X follows a small increase from NSac to Pic monomers because of the different intramolecular environments where $\mathrm{X}$ is embedded. Indeed, in the $\mathrm{N}$-halopicolinium monomers $(\mathrm{Br}-\mathrm{Pic})^{+}$and $(\mathrm{I}-\mathrm{Pic})^{+}$, in gas phase, the halogen charges amount to $\mathrm{Br}=+0.36|e|$ and $\mathrm{I}=+0.51|e|$ (see Table $\mathrm{S} 1$ in ESI). The dependence of the net positive charge of $\mathrm{Br}$ with the increasing power of electron withdrawing groups, has been determined in a series of related molecules such as $\mathrm{MeCON}(\mathrm{Me}) \mathrm{Br}, \mathrm{HCONHBr}, \mathrm{N}-$ bromophtalimide and $\left(\mathrm{CF}_{3}\right) \mathrm{CON}\left(\mathrm{CF}_{3}\right) \mathrm{Br}$. (See Figures S13-S16 in ESI).

In order to understand the crystalline influence on the position and on the interactions of $\mathrm{X}$ with the donor and the acceptor moieties within adducts, we have investigated their dependences with an external electric field $\varepsilon$ applied along the $\mathrm{N}_{\mathrm{Sac}} \bullet \bullet \mathrm{X} \bullet \bullet \mathrm{N}^{\prime}$ 'Pic direction, as explained at the beginning of this section. Hence, starting with the adduct at the experimental geometry, we have first optimized the position of $\mathrm{X}$ at $\varepsilon=0$, keeping frozen the rest of the atoms in the adduct. Then, we have increased the magnitude of $\varepsilon$, letting $X$ to optimize between $\mathrm{N}_{\text {Sac }}$ and $\mathrm{N}^{\text {Pic }}$, while the other atoms in the adduct are kept at the experimental frozen geometry. For each $\varepsilon$, Table 3 gathers the $\mathrm{N}_{\mathrm{Sac}} \bullet \bullet \mathrm{X}$ and $\mathrm{X} \bullet \bullet \mathrm{N}^{\prime}$ Pic distances, the topological and energetic properties of $\rho(\mathbf{r})$ at the corresponding BCPs. 
Table 3 Topological properties at the $\mathrm{N}_{\mathrm{Sac}} \cdot \cdots \mathrm{X}$ (first lines) and $\mathrm{X} \cdot \bullet \mathrm{N}_{\text {pic. }}^{\prime}$ (second lines) bond critical points $(X=B r, I)$, as a function of the applied external electric field $\varepsilon$. Net atomic integrated charges $Q(X)$ for both halogen atoms are also indicated. Units are: $\varepsilon\left(\times 10^{-4}\right.$ a.u. $)$,

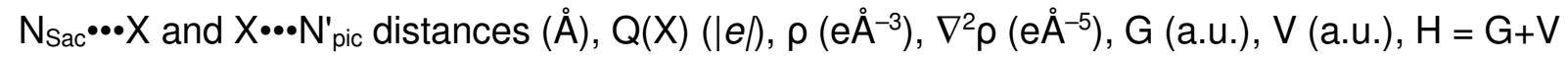
(a.u.), $|\mathrm{V}| / \mathrm{G}$ (dimensionless). $\varepsilon=1 \times 10^{-4}$ a.u. $\cong 0.051422 \mathrm{GV} / \mathrm{m}$.

\begin{tabular}{|c|c|c|c|c|c|c|c|c|c|c|}
\hline $\mathrm{X}$ & $\varepsilon$ & $\mathrm{N}_{\mathrm{Sac}} \cdots \mathrm{X}$ & $\mathrm{X} \cdots \mathrm{N}_{\text {pic. }}^{\prime}$ & $\mathrm{Q}(\mathrm{X})$ & $\rho$ & $\nabla^{2} \rho$ & $\mathrm{G}$ & $\mathrm{V}$ & $\mathrm{H}$ & $|\mathrm{V}| / \mathrm{G}$ \\
\hline \multirow[t]{10}{*}{$\mathrm{Br}$} & 0 & 1.962 & 2.209 & +0.300 & 0.890 & 1.32 & 0.082 & -0.151 & -0.069 & 1.83 \\
\hline & & & & & 0.538 & 2.90 & 0.053 & -0.076 & -0.023 & 1.43 \\
\hline & 20 & 1.997 & 2.175 & +0.297 & 0.827 & 1.69 & 0.077 & -0.136 & -0.059 & 1.77 \\
\hline & & & & & 0.582 & 2.72 & 0.056 & -0.084 & -0.028 & 1.50 \\
\hline & 40 & 2.036 & 2.135 & +0.295 & 0.760 & 2.05 & 0.071 & -0.120 & -0.050 & 1.70 \\
\hline & & & & & 0.636 & 2.48 & 0.060 & -0.093 & -0.034 & 1.57 \\
\hline & 60 & 2.078 & 2.093 & +0.295 & 0.693 & 2.38 & 0.065 & -0.106 & -0.041 & 1.62 \\
\hline & & & & & 0.697 & 2.18 & 0.064 & -0.105 & -0.041 & 1.65 \\
\hline & 80 & 2.120 & 2.051 & +0.296 & 0.632 & 2.65 & 0.061 & -0.094 & -0.033 & 1.55 \\
\hline & & & & & 0.763 & 1.82 & 0.069 & -0.119 & -0.050 & 1.73 \\
\hline \multirow[t]{12}{*}{$\mathbf{I}$} & 0 & 2.154 & 2.369 & +0.459 & 0.685 & 2.80 & 0.074 & -0.119 & -0.045 & 1.61 \\
\hline & & & & & 0.453 & 2.64 & 0.046 & -0.065 & -0.019 & 1.41 \\
\hline & 20 & 2.182 & 2.341 & +0.459 & 0.646 & 2.76 & 0.069 & -0.109 & -0.040 & 1.58 \\
\hline & & & & & 0.483 & 2.60 & 0.049 & -0.070 & -0.022 & 1.45 \\
\hline & 40 & 2.214 & 2.310 & +0.459 & 0.605 & 2.74 & 0.064 & -0.099 & -0.035 & 1.55 \\
\hline & & & & & 0.516 & 2.56 & 0.052 & -0.077 & -0.025 & 1.49 \\
\hline & 45 & 2.222 & 2.301 & +0.460 & 0.595 & 2.73 & 0.063 & -0.097 & -0.034 & 1.55 \\
\hline & & & & & 0.525 & 2.55 & 0.053 & -0.079 & -0.026 & 1.50 \\
\hline & 60 & 2.246 & 2.277 & +0.460 & 0.565 & 2.73 & 0.059 & -0.090 & -0.031 & 1.52 \\
\hline & & & & & 0.554 & 2.52 & 0.056 & -0.085 & -0.029 & 1.53 \\
\hline & 80 & 2.279 & 2.244 & +0.461 & 0.527 & 2.73 & 0.055 & -0.081 & -0.026 & 1.48 \\
\hline & & & & & 0.593 & 2.48 & 0.060 & -0.094 & -0.034 & 1.57 \\
\hline
\end{tabular}


Recently, in the context of the analysis of polyiodide chains, ${ }^{26}$ the characterization of the critical points (CPs) of the $L$ function along bonding directions and close to BCPs has permitted to distinguish between intramolecular I-I and intermolecular I $\bullet \bullet I^{2}$ interactions, in particular when involving intermediate situations where the distance and the topological properties at BCP only $\left(\nabla^{2} \rho_{\mathrm{BCP}}>0\right)$ make difficult to conclude. Indeed, the nature of the interaction of I-atoms with their environment results in a $(3,-3) \mathrm{CP}$ of $L$ closer to BCP for bonding interactions with shared-shell or covalent character, whereas $(3,+1)$ CPs appear for interatomic interactions involving intermolecular closed-shell interactions. In the case of the NISac and (I-Pic) ${ }^{+}$ monomers (Figure 4), we observe a $(3,-3)$ CPs of $L$ closer to the BCP of $\mathrm{N}_{\mathrm{Sac}}-\mathrm{I}$ and of I-N'Pic bonding interactions, whereas in the outer part of the molecules, a couple of $(3,+1)$ and $(3,-1)$ CPs appear behind the I-atom along the bonding direction.

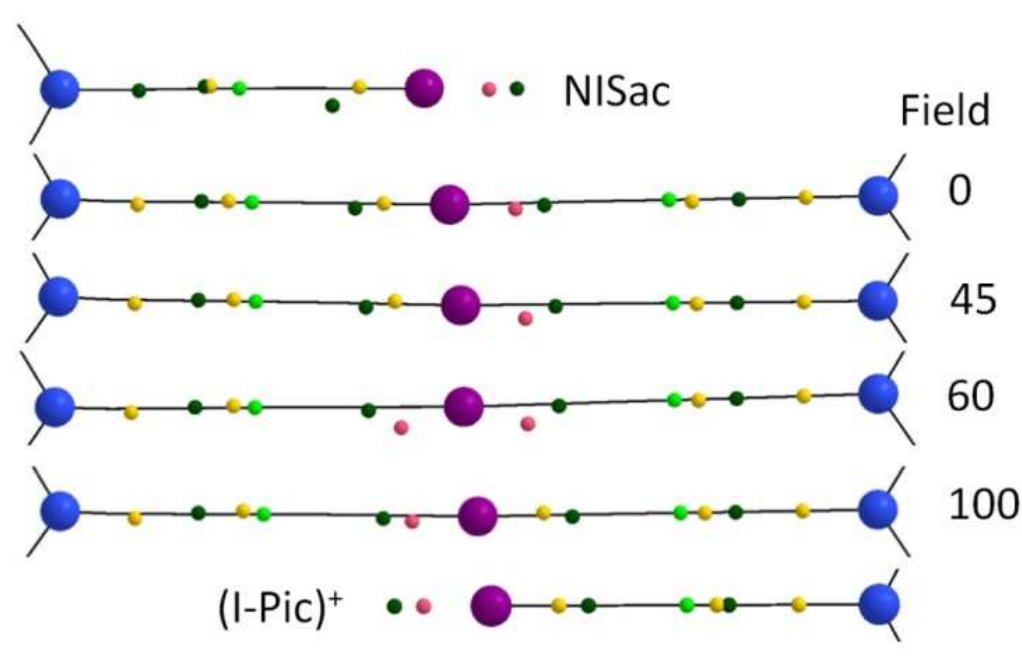

Fig. 4 Details of the topology of the $L(\mathbf{r})=-\nabla^{2} \rho(\mathbf{r})$ function around the iodine atom. From top to bottom: NISac monomer, NISac $\cdot P i c$ adduct at $\varepsilon$ electric field values of $0,45 \times 10^{-4}, 60 \times 10^{-4}$ and $100 \times 10^{-4}$ a.u., and (I-Pic) $)^{+}$cation. Selected CPs of the $L$-function are represented as small spheres: $(3,-3)$ yellow, $(3,-1)$ dark green, and $(3,+1)$ pink. The $(3,+3)$ CPs are not observed. Atoms are displayed as large spheres (I: violet, N: blue). The $(3,-1)$ BCPs of $\rho(\mathbf{r})$ are depicted as light green spheres. Detailed L-maps are given in the ESI (Figures S1-S6).

In the adduct, with I optimized at $\varepsilon=0$, the type of CPs are quite similar than those observed in the NISac and (I-Pic) ${ }^{+}$monomers. The unique difference is found within the I-basin (i.e. between both BCPs), where the couple of $(3,+1)$ and $(3,-1)$ CPs is only observed at the acceptor side and the couple of $(3,-3)$ and $(3,-1)$ CPs is still observed at the donor side. This last trend points again to the fact that the I-atom is not transferred to the acceptor. Hence, the positioning of the $(3,-3)$ and $(3,+1)$ CPs within the I-basin permits to characterise whether the I-atom is 
associated to the donor or to the acceptor molecule. Additionally, the $(3,-1) \mathrm{CPs}$, which behave as 1D local minima of $L$ along the bonding direction, are always found intercalated between a couple of $(3,-3)$ CPs or between a couple of $(3,-3)$ and $(3,+1)$ CPs. This is a straightforward consequence of the continuity of the function and the 1D local maxima of $L$ displayed at $(3,-3)$ and $(3,+1)$ CPs along the bonding direction. It should be noted that local maxima/minima of $L$ point to local largest/smallest concentration of $\rho$ in regions where $L>0$, and conversely to local smallest/largest depletion of $\rho$ in regions where $L<0$. Accordingly, these 1D maxima/minima of the L-function along bonding directions correspond to generalized charge concentration/charge depletion (CC/CD) sites, which are found alternated along the bond paths.

Then, applying an electric field that pushes the I-atom from the donor to the acceptor, a similar structure of CPs is maintained as long as $\varepsilon \leq 0.0045$ a.u. (at $\varepsilon=0.0045$ a.u. $=2.31$ $\mathrm{GV} / \mathrm{m}$ the position of I within the adduct is very close to that found in the experimental structure). However, with $\varepsilon=0.0060$ a.u. $=3.09 \mathrm{GV} / \mathrm{m}$, the system exhibits a new situation, where two $(3,+1)$ CPs are observed within the I-basin, actually at the donor and the acceptor sides while the $(3,-3) \mathrm{CP}$ at the donor side disappears. This corresponds to an intermediate description of the I-adduct into three NSac/I/Pic moieties. As a consequence, the iodine could be better interpreted as an iodonium cation between two charged moieties, namely NSac and Pic. Then, a further increase of the electric field $(\varepsilon=0.0080$ a.u. $=4.11 \mathrm{GV} / \mathrm{m})$ brings the adduct to fall into the third situation, where I has been transferred to the acceptor, as indicated by the position of the $(3,+1)$ and $(3,-3)$ CPs at the donor and the acceptor sides within the I-basin. At $\varepsilon=0.0100$ a.u. $=5.11 \mathrm{GV} / \mathrm{m}$, pushing even more the I-atom towards the picoline, the system does not exhibit any further variation on the topological CPs of $L$. Moreover, following the increase of the electric field within the range $0 \leq \varepsilon \leq 0.0100$ a.u., the concomitant decreased/increased shared-shell character of the I interactions at the donor/acceptor side of the adduct is clearly observed by the continuous variation of the topological and energetic properties at both BCPs. Hence, paralleling the changes in the topological CPs of $L$ with $\varepsilon$, the electron distribution properties at both BCPs also point the three regions where I can be found within the adduct. Indeed, whereas the values of $\rho$ and $\mid \mathrm{V} / / \mathrm{G}$ are greater at the donor than at the acceptor side for $\varepsilon \leq 0.0045$ a.u, they are almost equal at both sides for $\varepsilon=0.0060$ a.u., and greater at the acceptor side for $\varepsilon=0.0080$ a.u., thus indicating the three situations before, during and after the transfer of I. As the electric field miming the crystalline environment effect on the adduct is very close to $\varepsilon=0.0045$ a.u., the modification needed in the environment to bring the system from "neutral" NSac-X/Pic to "intermediate" NSac/X/Pic and to "ionic" NSac/X-Pic 
corresponds to an increase of $\Delta \varepsilon \leq+0.0015$ a.u. $(0.77 \mathrm{GV} / \mathrm{m})$ and of $\Delta \varepsilon \leq+0.0035$ a.u. (1.80 $\mathrm{GV} / \mathrm{m}$ ). These magnitudes are small (typically one order of magnitude lower than the electric fields found in molecular crystals) and quantify the variation on the electrostatic effect of the molecular environment that is needed to modify qualitatively the description of the adduct.

Similar calculations have been carried out with the NBSac and $(\mathrm{Br}-\mathrm{Pic})^{+}$monomers in gas phase, and with the Br-adduct upon the application of electric fields in the same range of magnitudes (Figure 5).

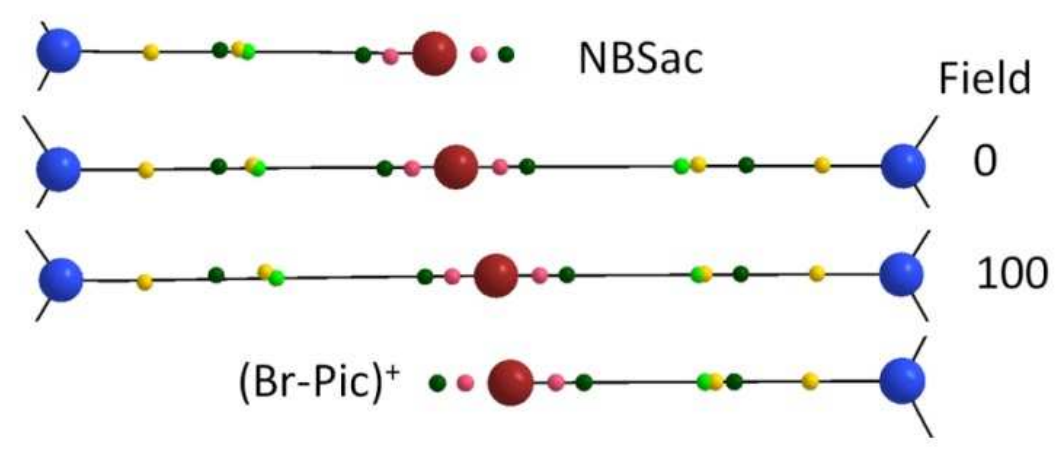

Fig. 5 Details of the topology of the $L(\mathbf{r})=-\nabla^{2} \rho(\mathbf{r})$ function around the bromine atom. From top to bottom: NBSac alone, NBSac.Pic adduct at $\varepsilon$ electric field values of 0 and $100 \times 10^{-4}$ a.u., and $(\mathrm{Br}-\mathrm{Pic})^{+}$cation. Selected $\mathrm{CPs}$ of the $L$-function are represented as small spheres: $(3,-3)$ yellow, $(3,-1)$ dark green, and $(3,+1)$ pink $((3,+3)$ CPs are not observed). Atoms are displayed as large spheres (Br: brawn, $\mathrm{N}$ : blue). The $(3,-1) \mathrm{BCPs}$ of $\rho(\mathbf{r})$ are depicted as small light green spheres. Detailed L-maps are given in the ESI (Figures S7-S10).

For both NBSac and (Br-Pic) $)^{+}$monomers in gas phase, the characteristic CPs of $L$ within the Br-basin, are of $(3,+1)$ type, even along the $\mathrm{N}_{\mathrm{Sac}}-\mathrm{Br}$ and $\mathrm{Br}-\mathrm{N}^{\prime}$ 'Pic bonding regions. This feature indicates that, in both NBSac and $(\mathrm{Br}-\mathrm{Pic})^{+}$monomers, bromine is already in the transition state ready to be transferred. Within the halogen-bonded adduct, the type of CPs does not change at any field belonging to the range $0 \leq \varepsilon \leq 0.0080$ a.u.. Again, following the increase of the electric field, the Br-position and the magnitudes of the topological and energetic properties at both BCPs indicate the decreased/increased shared-shell character of the $\mathrm{Br}$ interactions at the donor/acceptor sides, as for the I-adduct. However, as any of the monomers is able to link the Br-atom to neither $\mathrm{N}_{\text {Sac }}$ nor N'Pic by concentrating electrons from three directions $[(3,-3) \mathrm{CP}]$ instead of from only one $[(3,+1) \mathrm{CP}]$, the bromine atom cannot find the final transfer stage found with I in the I-adduct. Hence, in spite of the applied electric field, Br remains in the transition region along the full range of considered $\varepsilon$-fields, where it should be rather considered 
as a bromonium cation. As iodine brings a more positive charge than bromine, the former presents an easier deformable valence-shell (it is more distant from a filled electron-shell configuration) and is therefore less hard than bromine. This feature could explain the fact that whereas iodine can form a $(3,-3) \mathrm{CP}$ of $L$ (i.e. a $3 \mathrm{D}$ charge concentration) by deforming its shells, bromine is not able to build a similar distribution of charge along the full range of applied electric fields. With this respect, it is interesting to note that the net charges of iodine and bromine remain almost constant at any $\mathcal{E}$. This result indicates that they are not following environment effects, and charge transfer depends on the donor molecule only (values are very close to those of NXSac in gas phase, namely $\mathrm{Br}=+0.29 e$ and $\mathrm{I}=+0.43 e$ ).

On the other hand, the comparison of the topological and energetic properties at both BCPs of the $\mathrm{Br}$ - and I-adducts, points that, for the same variation $\Delta \mathcal{E}$, the weakening of the shared-shell character of the interaction with the donor, and the concomitant strengthening of the corresponding interaction with the acceptor is more important for $\mathrm{Br}$ - than for I-adduct. Accordingly, the $\mathrm{Br}$ atom reacts more promptly than I to the same environment influence, permitting an easier transfer. Hence, the interactions of $\mathrm{Br}$ with $\mathrm{N}_{\mathrm{Sac}}$ and $\mathrm{N}$ 'Pic balance to each other at $\varepsilon \approx 0.0060$ a.u. (the topological and energetic properties at both BCPs are very similar at this applied electric field), which closely corresponds to the same $\varepsilon$ magnitude than for balanced interactions with I, in spite of the more important shared-shell character at the donor side with $\mathrm{Br}$ along the considered range of $\varepsilon$ magnitudes. In this region of $\varepsilon$ magnitudes, both $\mathrm{Br}$ and I-adducts present $(3,+1) \mathrm{CPs}$ of $\mathrm{L}$ at both donor and acceptor sides, indicating that the system should be divided into three moieties, Sac/X/Pic, where $\mathrm{X}$ has halonium character. At the next applied field ( $\varepsilon=0.0080$ a.u.), all the topological and energetic properties at the acceptor side are larger in magnitude than at the donor side for both adducts, indicating that $\mathrm{X}$ $(\mathrm{X}=\mathrm{Br}, \mathrm{I})$ is actually associated to the acceptor molecule. However, only a $(3,-3) \mathrm{CP}$ of $L$ exhibits at the acceptor side with I, pointing that the transfer has been completed with I but not with Br. Actually, the I- and Br-adducts show respectively "ionic" and "intermediate" character with formal Sac/I-Pic and Sac/Br/Pic entities, where only Br conserves its halonium character as it is not completely associated neither to the donor nor to the acceptor. Finally, at $\varepsilon=0.0100$ a.u., the interaction at the donor/acceptor side further weakens/strengthens, but the adducts do not qualitatively evolve anymore. 


\section{Conclusion}

Based on X-ray crystal structures and topological analysis of the electron density, the comparison of the 4-picoline adducts of N-bromo- and N-iodosaccharin demonstrates that both systems belong to an intermediate region between pure closed-shell and pure shared-shell (covalent) interactions, a region where the electron density redistributes either to break or to form a chemical bond. The comparison of the topological and energetic properties of $\rho(\mathbf{r})$ at the analysed BCPs indicates a more important degree of covalence (i.e. shared-shell character) in both $\mathrm{N}_{\mathrm{Sac}} \bullet \bullet \mathrm{X}$ and $\mathrm{X} \cdot \bullet \mathrm{N}^{\prime}$ Pic regions of the adduct formed with the bromine atom. This result is contrary to the general rule that stronger halogen bonds are observed with iodine than with bromine (in a similar environment), showing that this rule only holds for "normal", i.e. relatively weak halogen bonds. In the extreme situations detailed above, the halogen bonds exhibit a sizeable covalent character, and the covalent bond strengths for $\mathrm{N}-\mathrm{I}$ and $\mathrm{N}-\mathrm{Br}$ bonds are indeed in reverse order.

As a consequence of the more important shared-shell character in both $\mathrm{N}_{\mathrm{Sac}} \bullet \bullet \mathrm{Br}$ and Br॰•N'Pic regions, in particular at the acceptor side, the Br-adduct exhibits a more important tightening degree than the I-adduct. At the same time, the former follows external environment effects with amplified magnitude compared to the latter, permitting an easier transfer with $\mathrm{Br}$ from the donor to the acceptor. Depending on the electron distribution in the $\mathrm{N}_{\mathrm{Sac}} \bullet \bullet \mathrm{X}$ and $\mathrm{X} \bullet \bullet N$ ' Pic regions, which determines the association of $\mathrm{X}$ with either the donor, or the acceptor or in a similar way to the donor and the acceptor, the adduct can be alternatively described as "neutral" NSacX/Pic, "ionic" $\mathrm{NSac}^{-}{ }^{+} \mathrm{X}-\mathrm{Pic}$ or "intermediate" NSac/X/Pic. These situations can be characterized by the topological CPs of the $L$-function and the topological properties at both BCPs. The 3D deformation that is needed in the $\rho(\mathbf{r})$ of the halogen atom to concentrate electrons in the bonding region to belong either to the donor or to the acceptor, is identified by a $(3,-3) \mathrm{CP}$ of $L$ in its atomic basin along the bonding direction with the corresponding donor/acceptor molecule, whereas a $(3,+1) \mathrm{CP}$ of $L$ appears at the opposite side along the bonding direction with the other acceptor/donor molecule. Within the "intermediate" region of interactions, where several geometries of $\mathrm{X}$ within the adduct can show, two $(3,+1) \mathrm{CPs}$ of $L$ appears in the halogen basin, one at each donor and acceptor side, indicating that the halogen atom does not fully belong neither to the donor nor to the acceptor. In the crystal structures, the adducts are identified as "neutral" NSac-I/Pic and "intermediate" NSac/Br/Pic, the latter with $\mathrm{Br}$ being close to the formal equivalent interactions but still more associated to the donor than to the acceptor. In intermediate situations, as $\mathrm{NSac} / \mathrm{Br} / \mathrm{Pic}$, halogen atoms should be rather 
considered as haloniums, whereas in "neutral" and "ionic" cases a halogen atom with partial net positive charge should be regarded. The more important charge separation observed in the Br-adduct with respect to the I-adduct $( \pm 0.27 v s . \pm 0.18 e)$ parallels the more important external electric field that is needed to be applied in the former to retrieve the experimental geometries of the halogen atom in the system $(2.96 v s .2 .35 \mathrm{GV} / \mathrm{m})$. The higher $\varepsilon$ magnitude observed with the Br-adduct is again pointing a more activated transfer with respect to the I-adduct. Indeed, the external electrostatic effect pushing $\mathrm{Br}$ within the Br-adduct ( $26 \%$ more important than for the I-adduct) favours its displacement towards the acceptor by an increasing polarization of the electron clouds (charge separation is more important) which weakens/strengthens the interaction with the donor/acceptor moieties. Finally, the use of applied electric fields appears as a very convenient tool for estimating crystalline molecular environment effects on the adducts, and can help to extract information on the supplementary electrostatic effect that is needed to transform "neutral" to "intermediate" and to "ionic" adducts.

\section{Experimental Section}

\section{Syntheses and Crystal Growth.}

NBSac and picoline. NBSac $\left(15 \mathrm{mg}, 5.72 \times 10^{-5} \mathrm{~mol}\right)$ was dissolved in ethylacetate $(2 \mathrm{~mL})$ and 4-picoline $\left(12 \mu \mathrm{L}, 11.44 \times 10^{-5} \mathrm{~mol}\right)$ was added. The solution was filtered to remove nondissolved particles and poured in a Durham tube. Crystals were made by vapour diffusion method with hexane. The sample was left at $2^{\circ} \mathrm{C}$ during 8 days in the dark. White needle-shaped crystals were obtained. M. p. $144-145^{\circ} \mathrm{C}$.

X-ray Crystallography. X-ray crystal structure collections were performed on a Nonius FR590 diffractometer or on an APEXII Bruker-AXS diffractometer equipped with a CCD camera and a graphite-monochromated Mo-K $\alpha$ radiation source $(\lambda=0.71073 \AA)$. Details of the structural analyses are summarized in Table 4. Absorption corrections were performed with SADABS. Structures were solved by direct methods using the SIR97 program, ${ }^{31}$ and then refined with fullmatrix least-square methods based on $F^{2}$ (SHELXL-97) ${ }^{32}$ with the aid of the WINGX program. ${ }^{33}$ All non-hydrogen atoms were refined with anisotropic atomic displacement parameters. $\mathrm{H}$ atoms were finally included in their calculated positions. 
Table 4. Crystallographic data

\begin{tabular}{|c|c|c|}
\hline & $\mathrm{Me}_{2} \mathrm{~N}(\mathrm{Br}) \mathrm{PyH}^{+}, \mathrm{Sac}^{-}$ & NBSac $\bullet P i c$ \\
\hline Formula & $\mathrm{C}_{14} \mathrm{H}_{14} \mathrm{BrN}_{3} \mathrm{O}_{3} \mathrm{~S}$ & $\mathrm{C}_{13} \mathrm{H}_{11} \mathrm{BrN}_{2} \mathrm{O}_{3} \mathrm{~S}$ \\
\hline $\mathrm{FW}\left(\mathrm{g} \cdot \mathrm{mol}^{-1}\right)$ & 384.25 & 355.21 \\
\hline System & triclinic & triclinic \\
\hline Space group & $\mathrm{P}-1$ & $\mathrm{P}-1$ \\
\hline $\mathrm{a}(\AA)$ & $7.2107(3)$ & $6.9455(13)$ \\
\hline $\mathrm{b}(\AA)$ & $8.5679(4)$ & $8.1993(14)$ \\
\hline$c(\AA)$ & $12.2391(5)$ & $13.825(2)$ \\
\hline$\alpha(\operatorname{deg})$ & $86.641(2)$ & $97.886(7)$ \\
\hline$\beta(\operatorname{deg})$ & $79.084(2)$ & $97.939(8)$ \\
\hline$\gamma(\operatorname{deg})$ & $87.121(2)$ & $109.479(8)$ \\
\hline$V\left(\AA^{3}\right)$ & $740.59(6)$ & $720.8(2)$ \\
\hline $\mathrm{T}(\mathrm{K})$ & $150(2)$ & $150(2)$ \\
\hline $\mathrm{Z}$ & 2 & 2 \\
\hline $\mathrm{D}_{\text {calc }}\left(\mathrm{g} \cdot \mathrm{cm}^{-1}\right)$ & 1.723 & 1.637 \\
\hline$\mu\left(\mathrm{mm}^{-1}\right)$ & 2.932 & 3.003 \\
\hline Total refls & 12374 & 9526 \\
\hline Abs corr & multi-scan & multi-scan \\
\hline $\mathrm{T}_{\min }, \mathrm{T}_{\max }$ & $0.639,0.768$ & $0.730,0.942$ \\
\hline$\theta_{\max }\left({ }^{\circ}\right)$ & 27.498 & 27.609 \\
\hline Uniq refls & 3369 & 3248 \\
\hline $\mathrm{R}_{\text {int }}$ & 0.0346 & 0.0242 \\
\hline Uniq refls $(\mathrm{I}>2 \sigma(\mathrm{I}))$ & 3079 & 2872 \\
\hline $\mathrm{R}_{1}$ & 0.0347 & 0.0263 \\
\hline $\mathrm{wR}_{2}$ (all data) & 0.111 & 0.0852 \\
\hline GOF & 1.147 & 1.174 \\
\hline Res. dens. (e $\left.\AA^{-3}\right)$ & $-0.561,0.131$ & $-0.521,0.103$ \\
\hline CCDC & 1528818 & 1528817 \\
\hline
\end{tabular}




\section{Acknowledgments}

We thank the Université de Rennes 1 for financial support to I. N. This work was granted access to the HPC resources of CCRT/CINES/IDRIS under the allocation A0010807449 made by GENCI.

\section{References}

${ }^{1}$ G. Cavallo, P. Metrangolo, R. Milani, T. Pilati, A. Priimagi, G. Resnati and G. Terraneo, Chem. Rev., 2016, 116, 2478-2601.

${ }^{2}$ L. C. Gilday, S. W. Robinson, T. A. Barendt, M. J. Langton, B. R. Mullaney, P. D. Beer, Chem. Rev., 2015, 115, 7118-7195.

3 (a) M. Andrzejewski, A. Olejniczak, A. Katrusiak, A. CrystEngComm, 2012, 14, 6374-6376; (b) C. B. Aakeröy, A. M. Beatty, K. R.Lorimer, Struct. Chem., 1999, 10, 229-242; (c) C. B. Aakeröy, C. L. Spartz, S. Dembowski, S. Dwyre, J. Desper. IUCrJ 2015, 2, 498-510.

4 J . D. Wuest, J. Am. Chem. Soc., 2001, 113, 4696-4698.

5 G. R. Desiraju, Angew. Chem. Int. Ed. Engl., 1995, 34, 2311-2327.

${ }^{6}$ (a) E. Corradi, S. V. Meille, M. T. Messina, P. Metrangolo, G. Resnati, Angew. Chem., Int. Ed., 2000, 39, 1782-1786; (b) C. B. Aakeröy, M. Fasulo, N. Schultheiss, J. Desper, C. Moore, J. Am. Chem. Soc., 2007, 129, 13772-13773; (c) C. B. Aakeröy, P. D. Chopade, J. Desper, Cryst. Growth Des., 2011, 11, 5333-5336; (d) C. B. Aakerôy, N. C. Schlutheiss, A. Rajbanshi, J. Desper, C. Moore, Cryst. Growth Des., 2009, 9, 432-441.

7 (a) S. Tothadi, G. R. Desiraju, Chem. Commun., 2013, 49, 7791-7793; (b) S. Tothadi, P. Sanphui, G. R. Desiraju, Cryst. Growth Des., 2014, 14, 5293-5302.

8 (a) P. Metrangolo, F. Meyer, T. Pilati, G. Resnati, G. Terraneo, Angew. Chem., Int. Ed., 2008, 47, 6114-6127; (b) P. Politzer, J. S. Murray, T. Clark, Phys. Chem. Chem. Phys., 2010, 12, 7748-7757; (c) E. Parisini, P. Metrangolo, T. Pilati, G. Resnati, G. Terraneo, Chem. Soc. Rev., 2011, 40, 2267-2278.

9 (a) T. Bjorvatten, Acta Chem. Scand., 1968, 22, 410; (b) B. Borgen, O. Hassel, C.

Römming, Acta Chem. Scand., 1962, 16, 2469-2470.

${ }^{10}$ G. R. Desiraju, R. L. Harlow, J. Am. Chem. Soc., 1989, 111, 6757-6764.

${ }^{11}$ K. Rissanen, M. Haukka, Top. Curr. Chem., 2015, 359, 77-90. 
${ }^{12}$ (a) A.-C. C. Carlsson, M. Uhrbom, A. Karim, U. Brath, J. Gräfenstein, M. Erdélyi, CrystEngComm, 2013, 15, 3087-3092; (b) S. B. Hakkert, M. Erdelyi, J. Phys. Org. Chem., 2015, 28, 226-233; (c) M. Bedin, A. Karim, M. Reitti, A.-C. C. Carlsson, F. Topić, M.

Cetina, F. Pan, V. Havel, F. Al-Ameri, V. Sindelar, K. Rissanen, J. Gräfenstein, M;

Erdélyi, Chem. Sci., 2015, 6, 3746-3756 and references therein.

${ }^{13}$ (a) A.-C. C. Carlsson, J. Gräfenstein, A. Budnjo, J. L. Laurila, J. Bergquist, A. Karim, R. Kleinmaier, U. Brath, M. Erdélyi, J. Am. Chem. Soc., 2012, 134, 5706-5715; (b) A.-C. C. Carlsson, J. Gräfenstein, J. L. Laurila, J. Bergquist, M. Erdélyi, Chem. Commun., 2012, 48, $1458-1460$.

${ }^{14}$ D. Dolenc, M. Modec, New J. Chem., 2009, 33, 2344-2349.

${ }^{15}$ O. Makhotkina, J. Lieffrig, O. Jeannin, M. Fourmigué, E. Aubert, E. Espinosa, Cryst. Growth Des. 2015, 15, 3464-3473.

${ }^{16}$ (a) D. Urankar, I. Rutar, B. Modec, D. Dolenc, Eur. J. Org. Chem., 2005, 2349-2353; (b) L. Bailey, S. T. Handy, Tetrahedron Lett., 2011, 52, 2413-2414; (c) S. P. L. De Souza, J. F. M. Da Silva, M. C. S. De Mattos, J. Braz. Chem. Soc., 2003, 14, 832-835; (d) D. Dolenc, Synlett, 2000, 544-546.

${ }^{17}$ (a) T. Shirman, D. Freeman, Y. D. Posner, I. Feldman, A. Faccheti, M. E. van der Boom, J. Am. Chem. Soc., 2008, 130, 8162-8163; (b) T. Shirman, M. Boterashvili, M. Orbach, D. Freeman, L. J. W. Shimon, M. Lahav, M. E. van der Boom, Cryst. Growth Des., 2015, 15, $4756-4759$.

${ }^{18}$ Y. Le Gal, D. Lorcy, O. Jeannin, F. Barrière, V. Dorcet, J. Lieffrig, M. Fourmigué CrystEngComm, 2016, 18, 5474-5481.

${ }^{19}$ (a) P. Auffinger, F. A. Hays, E. Westhof, P. S. Ho, Proc. Natl. Acad. Sci. U. S. A., 2004, 101, 16789-16794; (b) A. R. Voth, P. Khuu, K. Oishi, P. S. Ho. Nat. Chem., 2009, 1, $74-79$.

${ }^{20}$ S. J. Clark, M. D. Segall, C. J. Pickard, P. J. Hasnip, M. J. Probert, K. Refson, M. C. Payne, M. C. Z. Kristallogr., 2005, 220, 567-570.

${ }^{21}$ B. Nepal, S. Scheiner, Phys. Chem. Chem. Phys., 2016, 18, 18015-18023.

${ }^{22}$ E. Aubert, S. Lebègue, M. Marsman, T. T. T. Bui, C. Jelsch, S. Dahaoui, E. Espinosa, J. Angyan, J. Phys. Chem. A, 2011, 115, 14484-14494.

${ }^{23}$ R. F. W. Bader, Atoms in Molecules: A Quantum Theory; Oxford University Press: Oxford, 1990.

${ }^{24}$ E. Espinosa, E. Molins, C. Lecomte, Chem. Phys. Lett., 1998, 285, 170-173

${ }^{25}$ E. Espinosa, I. Alkorta, J. Elguero, E. Molins, J. Chem. Phys., 2002, 117, 5529-5542 
${ }^{26}$ K. Lamberts, P. Handels, U. Englert, E. Aubert and E. Espinosa, CrystEngComm., 2016, 18, 3832-3841.

27 (a) M. E. Brezgunova, E. Aubert, S. Dahaoui, P. Fertey, S. Lebègue, C. Jelsch, J. G. Ángyán and E. Espinosa, Cryst. Growth Des., 2012, 12, 5373-5386; (b) M. E. Brezgunova, J. Lieffrig, E. Aubert, S. Dahaoui, P. Fertey, S. Lebègue, J. G. Ángyán, M. Fourmigué, and E. Espinosa, Cryst. Growth Des., 2013, 13, 3283-3289.

${ }^{28}$ I. Nicolas, O. Jeannin, D. Pichon, M. Fourmigué, CrystEngComm 2016, 18, 9325-9333.

${ }^{29}$ E. R. Milton, A. E. Douglas, H. B. Dunford, J. Chem. Phys. 1961, 35, 1202-1210

${ }^{30}$ L. F. Phillips, Can. J. Chem., 1968, 46, 1429-1434.

${ }^{31}$ A. Altomare, M. C. Burla, M. Camalli, G. Cascarano, C. Giacovazzo, A. Guagliardi, A. G. G. Moliterni, G. Polidori, R. Spagna, J. Appl. Cryst., 1999, 32, 115-119.

${ }^{32}$ G. M. Sheldrick, Acta Crystallogr., 2008, A64, 112-122.

${ }^{33}$ L. J Farrugia, J. Appl. Cryst., 1999, 32, 837. 

